\title{
Anabases
}

ANABASES Traditions et réceptions de l'Antiquité

$7 \mid 2008$

Varia

\section{BANSAT-BOUDON \& R. LARDINOIS (éd.), Sylvain Lévi (1863-1935), études indiennes, histoire sociale. Actes du colloque tenu à Paris les 8-10 octobre 2003}

\section{Annick Fenet}

\section{OpenEdition}

\section{Journals}

Édition électronique

URL : http://journals.openedition.org/anabases/2546

DOI : 10.4000/anabases. 2546

ISSN : 2256-9421

Éditeur

E.R.A.S.M.E.

Édition imprimée

Date de publication : 1 mars 2008

Pagination : 275-276

ISSN : 1774-4296

\section{Référence électronique}

Annick Fenet, «L. BANSAT-BOUdon \& R. LARDinoIs (éd.), Sylvain Lévi (1863-1935), études indiennes, histoire

sociale. Actes du colloque tenu à Paris les 8-10 octobre 2003 ", Anabases [En ligne], 7| 2008, mis en ligne le 01 décembre 2011, consulté le 22 septembre 2020. URL : http://journals.openedition.org/anabases/ 2546 ; DOI : https://doi.org/10.4000/anabases.2546

Ce document a été généré automatiquement le 22 septembre 2020

(c) Anabases 


\title{
L. BANSAT-BOUDON \& R. LARDINOIS (éd.), Sylvain Lévi (1863-1935), études indiennes, histoire sociale. Actes du colloque tenu à Paris les 8-10 octobre 2003
}

\author{
Annick Fenet
}

\section{RÉFÉRENCE}

L. BANSAT-BOUDON \& R. LARDINOIS (éd.), Sylvain Lévi (1863-1935), études indiennes, histoire sociale. Actes du colloque tenu à Paris les 8-10 octobre 2003 (Bibliothèque de l'École des Hautes Études, Sciences Religieuses 130), Turnhout, Brepols, 2007, 536 p.

65 euros / ISBN 978-2-503-52447-4.

1 Dans la continuité du précieux recueil Correspondances orientalistes entre Paris et SaintPétersbourg (1887-1935) (Paris, Mémoires de l'Académie des Inscriptions et Belles-Lettres XXVI, 2002; écrit en collaboration avec G.M. Bongard-Levin et A.A. Vigasin), le sociologue Roland Lardinois, chercheur au Centre d'études de l'Inde et de l'Asie du SudEst, a porté plus précisément son attention sur l'une des grandes figures de l'indianisme français. Il a organisé en 2003, avec l'éminente sanskritiste L. BansatBoudon (EPHE), un colloque international sur Sylvain Lévi qui fut à la fois « épigraphiste, numismate, géographe, ethnographe, philosophe [...], linguiste, dans tous les cas philologue, et par-dessus tout, peut-être, historien » (L. Bansat-Boudon, p. 22), colloque dont les volumineux actes paraissent aujourd'hui. En dehors de toute « hagiographie » (R. Lardinois, p. 17), S. Lévi présente en effet un double intérêt, à la fois par son œuvre scientifique, prolifique (plus de 350 titres) et brillante d'intelligence et de culture, et par l'engagement de l'homme. C'est pourquoi l'ouvrage s'articule en deux orientations : 
la première autour de l'exégèse de ses travaux et de l'histoire des disciplines (8 communications), la seconde autour du contexte de la III ${ }^{\mathrm{e}}$ République et de l'entourage familial ou scientifique du savant (13 communications).

Élève d'Abel Bergaigne, membre de la Société asiatique dès 1884, élu à 31 ans professeur au Collège de France à la "chaire de langue et littérature sanscrite " (sic) et directeur d'études à l'EPHE (1894), cet orientaliste précoce ne resta pas simplement un sanskritiste de cabinet; voyageur infatigable, il parcourut toute sa vie l'Inde, le Tibet, le Népal (communication de G. Toffin, p. 375-389), le Japon, la Russie. Ami du poète indien Rabindranath Tagore, il enseigna même sur son invitation à l'université de Santiniketan (Bengale) en 1921-1922. Les contributions de G.-J. Pinault (p. 111-144) et de C. Scherrer-Schaub (p. 173-190) sont à cet égard particulièrement éclairantes sur l'indianisme de Sylvain Lévi et sa place dans l'histoire des études bouddhiques, tandis que celle de E. Gerow (p. 91-101) met en avant la notion d'« humanisme » récurrente dans la pensée de S. Lévi. Celle-ci a aussi fortement marqué les esprits du $\mathrm{xx}^{\mathrm{e}} \mathrm{s}$., influençant tant les intellectuels indiens (communication de S. Bayly, p. 193-212) qu'inspirant le poète russe Constantin Balmont (1867-1942) (communication de G.M. Bongard-Levin, p. 213-219) ou formant des «disciples» francophones [communication de M. Fournier, p.221-236, sur le sociologue Marcel Mauss (1872-1950); celle de B. Kaganovitch, p. 237-251, sur la sanskritiste russe Nadine Stchoupak (1886-1941) ; celle de P. Servais, p. 343-360, sur le belge Louis de La Vallée Poussin (1869-1938), une contribution de manière générale très intéressante sur l'orientalisme belge].

3 Orientaliste, juif, républicain et humaniste, mais dans quel ordre? Plusieurs communications apportent des éléments de réponse à la question. Doublement issu de lignées juives alsaciennes (cf. R. Lardinois, p. 267-288: sur sa " parentèle »), né et élevé à Paris, Sylvain Lévi appartient à la communauté juive de la seconde moitié du XIX ${ }^{\mathrm{e}} \mathrm{s}$. qui souhaite avant tout l'intégration à la république française. Son ralliement à la cause dreyfusarde le mena cependant à la direction, durant l'entre-deux-guerres mondiales, de l'Alliance israélite universelle (1920-1935). L'apparente contradiction entre son judaïsme et son universalisme fut l'objet de bien des attaques, y compris par les siens qui critiquèrent son refus du sionisme (contributions de H. Laurens, p. 289-300 et G. Weill, p.391-420). Son patriotisme, manifesté durant la Grande Guerre (communication de P.E. Landau, p. 253-265), n'est pas sans conséquence sur ses rapports avec l'indianisme allemand (communication de P. Rabault, p. 301-342) ; notons encore à ce titre que Sylvain Lévi mit un point d'honneur à enseigner à l'Université de Strasbourg (1919-1921), une fois qu'elle fut rattachée à la France.

4 Les auteurs ont su exploiter au mieux les sources : l'œuvre imprimée du Maitre avant tout, mais aussi les archives éclatées le concernant au premier plan: archives parisiennes de l'indianiste, malheureusement lacunaires, transportées par les aléas de l'histoire jusqu'à Moscou et sorties de l'ombre il y a seulement une dizaine d'années ; archives familiales conservées par sa petite-fille; archives de l'Alliance israélite universelle (Paris); archives du Collège de France. De surcroît, cet ensemble de communications est complété de présentations « liminaires» de Sylvain Lévi (p. 9-32) et enrichi de très utiles index thématiques, précis et détaillés (p. 455-502), d'une bibliographie générale (p. 503-526) et, chose plus rare qui mérite d'être signalée, d'une présentation de tous les auteurs (p. 449-454) précisant leurs domaines de recherches et leurs titres bibliographiques - invitation au lecteur à exercer un regard 
historiographique sur les contributions, ou simplement à fournir de nouvelles pistes de lectures, voire à motiver des rencontres futures pour continuer les échanges. Dans le champ ouvert de l'histoire de l'orientalisme français fin XIXe-premier tiers du Xxe siècle, voilà donc un ouvrage à clefs multiples qui restera, n'en doutons pas, un ouvrage de référence.

\section{AUTEURS}

\section{ANNICK FENET}

Université de Paris X

annick.fenet@mae.u-paris10.fr 